\title{
A POLÊMICA DO INÍCIO DA VIDA: uma questão de perspectiva de interpretação
}

\section{The controversy about the beginning of life: a matter of perspective of interpretation}

\section{Rogério Miranda de Almeida ${ }^{[a]}$,Vanessa Roberta Massambani Ruthes ${ }^{[b]}$}

[a] Doutor em Filosofia pela Universidade de Metz (França) e em Teologia pela Universidade de Estrasburgo (França), professor dos Programas de Pós-Graduação em Filosofia e Teologia da Pontifícia Universidade Católica do Paraná (PUCPR), Curitiba, PR - Brasil, e-mail: r.mirandaalmeida@gmail.com

${ }^{[b]}$ Filósofa, especialista em Bioética e Mestranda no Programa de Pós-Graduação em Teologia da Pontifícia Universidade Católica do Paraná (PUCPR), Curitiba, PR - Brasil, e-mail: vanessa_ruthes@yahoo.com.br

\section{Resumo}

A polêmica consiste numa divergência entre partes acerca de um tema ou opinião. No que diz respeito ao início da vida, esse desacordo está estabelecido. Há um choque entre a opinião das ciências, das várias culturas e religiões, isso porque cada uma delas possui um conteúdo axiológico próprio. Tendo em vista que os valores são diretamente responsáveis pela interpretação que se doa ao conhecimento obtido, pretende-se demonstrar a perspectividade desse. É importante ressaltar que tal realidade não constitui um relativismo. Assim, pode-se afirmar que o discurso acerca do início da vida é perspectivo e não unilateral, e que não há uma única verdade acerca do assunto, mas pontos de vista diferente e divergentes.

Palavras-chave: Início da vida. Bioética. Perspectivismo. 


\section{Abstract}

A controversy consists of a divergence among different points of view about a subject or opinion. When speaking about the beginning of life, this discord is set up. There's a conflict among several cultures, religions and science's opinion, because each one of them has a unique axiological content. Having in mind that values are directly responsible for interpretation that's given to acquired knowledge, it's intended to demonstrate its perceptivity. It's important to emphasize that such a reality is not a relativism. Thus it is inferred that the speech about the beginning of life is a perspective-based one, not unilateral, and there's not just one truth about that subject, but different and divergent points of view.

Keywords: Beginning of life. Bioethics. Perspectivism.

Um dos grandes temas discutidos na atualidade, no campo da bioética, é a questão do início da vida humana. Estabelecer o momento no qual ela principia é central, pois auxiliaria na resolução de polêmicas como o aborto, a reprodução assistida e a manipulação de embriões excedentes de clínicas que praticam tal técnica. Contudo, essa não é somente uma tarefa das ciências biológicas, pois a delimitação do início da vida humana envolve os conceitos de dignidade humana, pessoalidade e transcendência. Constitui-se, portanto, num trabalho conjunto com as das ciências religiosas, filosóficas, antropológicas e sociológicas.

Percebe-se nesse ponto que há, ou melhor, deve haver a integração de dois discursos: o científico (baseado em dados objetivos) e o valorativo (baseado em dados culturais). Contudo, há críticos que ressaltam que todo juízo objetivo é carregado de interpretações valorativas. Sendo que neste ponto surgem divergências, tendo em vista que cada área do conhecimento justifica uma visão diferenciada a partir de um conjunto valorativo controverso. $\mathrm{O}$ perspectivismo moral, característico da atualidade, auxilia na proliferação dessa polêmica, dificultando, portanto o consenso.

Assim, esse ensaio pretende abordar a polêmica em torno da questão do início da vida humana como resultado da estrutura axiológica perspectivista da pós-modernidade. 


\section{O início da vida: diferentes posições}

\section{A origem da vida e as teorias tradicionais}

A temática da origem da vida é algo deliberado nas diferentes culturas desde a origem da humanidade. Muitos povos criaram todo um imaginário mítico visando a responder a indagação de como e quando a vida humana se originou. Procuravam explicar o que dificilmente pode ser explicado, mas que precisa ser compreendido. É necessário entender que o mito servia para realizar a ligação entre o individualizado, particularizado (mito-pessoal) com o social (família, sociedade, cultura) e com os mitos universais, através de arquétipos coletivos, buscando preencher lacunas de compreensão segundo a cultura de um povo. Assim, pode-se afirmar que várias tradições foram erigidas sobre os mitos, sendo que com o passar do tempo, por meio de um processo, essas visões se tornaram complexas, fundamentadas por valores de uma cultura específica (TARNAS, 2000, p. 31-40).

É necessário ressaltar também que as grandes tradições influentes na atualidade são as que descendem das diferentes religiões. Em especial, abordarse-á cinco: Catolicismo/Cristianismo, Judaísmo, Islamismo, Hinduísmo e Budismo. Dessas, três defendem que a vida humana começa na fecundação, uma que começa no quadragésimo dia após a fecundação e a outra que a vida não se inicia, tendo em vista que é um processo contínuo e ininterrupto. Aqui, poder-seia questionar: por que e como defendem essas posições? Para compreender é necessário ter em mente a construção mitológica de cada uma.

No Catolicismo houve todo um processo, até que em 1869 foi condenada toda e qualquer interrupção voluntária da gravidez. Em outras palavras, foi estabelecido - como ressaltavam grandes teólogos como Tertuliano e Alberto Magno - que a hominização era imediata, pois logo após a fecundação já está constituído um ser humano em processo de formação (BARCHIFONTAINE, 2004, p. 111). No caso do Judaísmo, que acredita que o embrião é ser humano a partir do quadragésimo dia, é necessário ter em mente a cultura que fundamenta tal visão. O número 40 e suas conjunções são significativos na história do Povo de Israel. Sempre é símbolo de vida nova, ou de libertação, por exemplo, após 400 anos de escravidão, são libertos, após 40 anos do deserto adentram à terra prometida. Enfim, os 40 dias indicam que a criança está pronta para iniciar um processo de vida, de vida em Deus (BAECK, 1993, p. 35). 
O Islamismo é uma religião que, pautada em seu livro sagrado, afirma que Deus desempenha quatro funções fundamentais no Universo e na humanidade: criação, sustentação, orientação e julgamento. Sendo assim, acreditam que a vida se inicia, quando Deus a cria, quando o Deus único sopra a alma, ou seja, na fecundação (TARNAS, 2000, p. 197-201). O Hinduísmo acredita em sucessivas reencarnações que fazem parte de um processo de catarse. Contudo, ressaltam que a vida tem um início e um fim, sendo o início quando a alma se une ao corpo na fecundação e se desune do corpo na morte. Por fim, o Budismo, que também acredita na reencarnação, afirma que a vida é um processo contínuo e ininterrupto, portanto, não há necessariamente um início.

Concomitantemente ao processo narrado, a ciência foi passando por modificações e progressos que a fizeram acreditar e afirmar, em um primeiro momento, que a vida efetivamente se iniciava na fecundação. Contudo, devido a avanços na segunda metade do século XX e início do XXI, diferentes opiniões surgiram. Assim, primeiramente é necessário entender como esse processo se deu, para depois elencar as opiniões que atualmente geram debate.

\section{Os avanços científicos e a crise de conceitos}

Aproximadamente nos últimos 100 anos a humanidade assistiu as inúmeras descobertas que revolucionaram a concepção acerca da vida e de seu início. Essas mudanças começaram no século XIX, com a percepção de que todo ser vivo é formado por uma pequena parcela na qual está contida as características da vida: a célula. Posteriormente, identificou-se no núcleo dessa estrutura os cromossomos, nos quais o biólogo Thomas Hunt Morgan concluiu que se encontravam os genes, por meio dos quais eram transmitidas as características ao ser.

Em meados do século XX todo esse processo sofre um impulso fenomenal, pois, a partir dos estudos da biologia molecular ${ }^{1}$, tornou-se possível o descobrimento, em 1943, do DNA. Mas somente dez anos depois foi revelada a estrutura do ácido desoxirribonucleico, feita pelo biólogo James Watson e pelo físico Francis Crick, o qual afirmou que essa estrutura molecular trazia

1 Parte da biologia que estuda os ácidos nucléicos, as proteínas, a maneira como se expressam e se regulam os genes (SOUZA, 2004b, p. 40). 
consigo "novidades que são de considerável interesse para a biologia"2, representando assim um salto qualitativo nas ciências biológicas.

No ano de 1966 encerrou-se o processo de decodificação do DNA, que é composto de quatro bases químicas: adenina (A), citosina (C), guanina (G) e timina $(\mathrm{T})$, que são ligadas por pares às duas fitas que forma a dupla hélice desse ácido. A partir da década de 70 todo esse conhecimento foi aliado à tecnologia informacional, gerando novos avanços. Em 1971, chegou-se à era do DNA recombinante $^{3}$ e à primeira tentativa de clonagem, em 1973. As pesquisas se intensificam na década de 80 , gerando na década de 90 resultados e iniciativas. Como resultado cabe ressaltar a criação de Dolly, em 1997, uma ovelha clonada a partir de uma célula do corpo, e como iniciativa o Projeto Genoma Humano (PGH), que objetivava ${ }^{4}$ mapear e sequenciar todo o genoma humano.

No ano de 2000, quando foram anunciados os trabalhos realizados nos últimos dez anos pelo $\mathrm{PGH}$, percebeu-se que o conhecimento gerado dizia respeito às estruturas essenciais da vida. Paralelamente a todo esse processo houve um avanço muito grande na área da medicina que trabalha com tecnologias de reprodução, o que fez Bill Clinton, presidente dos Estados Unidos da América na época, afirmar: "isso equivale a aprender a linguagem com que Deus criara a vida" (SOUZA, 2004b, p. 34). Assim, um abalo profundo das concepções tradicionais se efetivou.

\section{Novos conceitos a partir dos avanços tecnocientíficos}

No item anterior, puderam-se perceber as modificações ocorridas com o desenvolvimento de conhecimentos e técnicas que proporcionaram à

2 Afirmação feita num artigo publicado em 1953 pela revista Nature e citado em reportagem feita por Okky de Souza (SOUZA, 2004a, p. 120).

3 Molécula de DNA na qual são enxertadas outras moléculas de DNA de outros organismos, da mesma espécie ou não (SOUZA, 2004b, p. 40)

4 Os objetivos específicos, para o início dos estudos, eram: estruturar um mapa genético e um mapa físico do genoma; sequenciar todo o genoma humano: melhorar as técnicas, desenvolver novas tecnologias e reduzir custos; mapear o sequenciamento de alguns organismos; desenvolver programas e bancos de dados contendo os mapas genéticos e físicos do genoma humano e de outros; desenvolver programas para estudar as implicações éticas em decorrência dos estudos; treinar pesquisadores; estimular a transferência da tecnologia para a indústria e para a comunidade. (SOUZA, 2004b, p. 32). 
humanidade manipular a "origem" da vida em si mesma. A partir desse cenário novas teorias surgiram, entre as quais se ressaltam a genética, a embriológica, a neurológica e a ecológica.

A genética defende a tese de que a vida de qualquer ser, inclusive o humano, tem início com a fecundação, pois a união dos gametas gera um código genético, constituindo, portanto, um novo ser em potência. A visão embriológica defende que a vida se inicia na terceira semana após a concepção, quando o embrião está formado. A visão neurológica afirma que a vida se inicia quando o sistema nervoso está, de forma primitiva, constituído, pois é o seu funcionamento que doa a possibilidade da vida. A ecológica, por sua vez, afirma que a vida se inicia quando o feto deixa o útero e interage com o mundo.

Essas quatro visões partem de interpretações diferentes: uma que a vida se inicia com a estruturação do genoma, ou com a formação do embrião, com a formação do sistema nervoso ou com a interação com os demais seres. Percebe-se assim que, por mais que se fundamentem em dados objetivos, sua interpretação não é neutra, é pautada em uma visão de mundo, que por sua vez provém de um conjunto axiológico.

\section{O discurso científico como discurso moral}

O item anterior foi encerrado com a afirmação de que todo juízo científico não pode mais ser compreendido como neutro, tendo em vista que tal é sempre fundamentado em um determinado conjunto axiológico. Para compreender tal afirmação é necessário ter em mente que a neutralidade científica defendida até meados da primeira metade do século XX principalmente pelos filósofos positivistas e pelos neopositivistas do Círculo de Viena - perdeu seu status quo.

\section{Círculo de Viena e os juízos positivos}

Uma corrente filosófica conhecida como o Círculo de Viena, começou sua especulação filosófica com a finalidade de proporcionar uma aclaração dos conceitos emitidos pela ciência positiva, neutra, pois afirmavam que a linguagem dessa estava povoada de noções metafísico-subjetivas. Esses foram influenciados 
por Ludwig Wittgenstein, que em sua obra Tractatus Logicus Philosophicus procura formular uma linguagem única e precisa, que pretende traçar os limites do que se pode pensar e representar pela linguagem com o objetivo de discernir a verdade das pretensões teóricas. Segundo o autor a filosofia não é uma teoria, mas uma atividade que busca esclarecer de forma lógica os pensamentos, tornando-os claros e bem delimitados (WITTGESTEIN, 1991a, p. 112). Não pode existir qualquer discurso metalinguístico sobre a relação entre a linguagem e o mundo, pois isso resultaria numa confusão entre "relações internas", que pertencem à forma mesma da linguagem e do mundo, e as "relações externas" entre as coisas e objetos encontráveis no mundo (APEL, 1994, p. 38).

A posição dos membros do Círculo de Viena era semelhante à de Wittgenstein. Eles tomam como ponto de partida o seguinte aforismo: "compreender uma proposição significa saber como estão as coisas no caso de ela ser verdadeira" (REALE, 1999, p. 59). Afirma também que a função específica da filosofia é procurar e clarificar o sentido das afirmações e das questões. O sentido de uma proposição consiste unicamente no fato de que ela expressa determinado estado de coisas, o qual é necessário mostrar. Portanto, se se quiser indicar o sentido de uma proposição, deve-se buscar transformálas por meio da introdução de definições sucessivas, até que seu significado possa ser demonstrado diretamente. $\mathrm{O}$ critério para determinar a veracidade ou falsidade de uma proposição consiste em que, sob determinadas condições, alguns acontecimentos se dêem efetivamente ou não, estabelecendo os limites e o sentido (REALE, 1999, p. 63).

Essa teoria é denominada de sistemas de constituição e também foi utilizada por Carnap, segundo o qual todas as proposições da ciência deveriam se apoiar nos dados da experiência imediata. O sentido de uma proposição deve expressar um estado de fato; se não expressa, não possui sentido e se constitui aparentemente assertiva. Por outro lado, se uma proposição expressa um estado de fato, possui significado e constitui-se verdadeira quando esse estado de fato existe, e falsa quando ele não existe (REALE, 1999, p. 70).

Percebe-se com esse pequeno esboço, que o círculo de Viena, ou o neopositivismo, como também é denominado, pretende somente reforçar a pretensa neutralidade e universalidade do discurso científico do positivismo, libertando-o por meio da elaboração de uma linguagem rigorosa, precisa, que se atém aos fatos (neutralidade) e que poderia ser utilizada e compreendida por todos (universalidade). 


\section{Linguagem, valor e conduta}

Há vários filósofos que discordam dessa posição e um deles é o próprio Wittgenstein, que em uma obra posterior, Investigações filosóficas, reconhece os "equívocos" que acabou por cometer no Tractatus. O mais central desses erros foi a pretensão de uma linguagem universal, que parte da ideia de que a linguagem é um conjunto de atividades uniformemente desempenhadas, vinculadas aos usos determinados e que podem servir em determinadas situações. Afirma ainda que o fator importante para a linguagem não é o significante, mas o significado, que, segundo sua concepção, nada mais é do que o uso desse naquela. Como o autor afirma: "Pode-se, para uma grande classe de casos de utilização da palavra 'significado', senão para todos os casos de sua utilização, explicá-la assim: a significação de uma palavra é o seu uso na linguagem" (WITTGENSTEIN, 1991b, §43).

Nessa perspectiva, elabora a noção de jogos de linguagem. Emprega esse termo para mostrar que o uso da linguagem segue regras específicas nos diferentes jogos, nos diferentes contextos e situações da vida. Para diferentes jogos, valem diferentes regras e sistemas de regras. Cada jogo deve ser entendido em separado: "quer-se estabelecer uma ordem no conhecimento do uso da linguagem; uma ordem para uma finalidade determinada; uma ordem dentre as muitas possíveis; não a ordem" (WITTGESNSTEIN, 1991b, §132). Jogos de linguagem são modos de condutas, do homem que pensa e fala, e que possibilitam a ele viver em sociedade.

Acerca de toda a questão dos jogos de linguagem abordada por Wittgenstein é que Karl Otto Apel, filósofo da terceira fase da Escola de Frankfurt, realizará a sua crítica a qualquer pretensa universalidade e neutralidade da teoria da ciência positiva. Para ele, essa não se pode pretender universal, pois se remete a várias comunidades de argumentação, com vários e diferentes jogos linguísticos, cujo pressuposto é a intersubjetividade. Não se pode pretender neutra, pois cada comunidade pressupõe, além de jogos de linguagem específicos, uma determinada ética: normas e valores. Pois a objetividade da ciência admite previamente uma comunidade de argumentação, o argumento sempre remete a uma comunidade de pensadores que chegam a uma compreensão consensual (RUSS, 1999, p. 83).

$\mathrm{O}$ autor refere toda a atividade a essa comunidade que está inserida numa subjetividade, que reintroduz a linguagem comum no próprio seio da 
ciência, que pretende ser unicamente fiel ao fato, mas se refere à determinados valores e não se mostra dessa maneira axiologicamente neutra. Essa comunidade, segundo a visão de Apel, não se limita ao conjunto factual, mas designa principalmente uma comunidade subjetiva. Observa-se, dessa maneira, que a perspectiva de Apel se projeta ao a priori da comunidade argumentativa, à sua própria subjetividade:

Mesmo o pensador que, de fato, é solitário, só pode explicar e submeter sua argumentação ao exame enquanto é capaz de interiorizar a discussão de uma comunidade potencial de argumentação no diálogo crítico - da alma consigo mesma. Evidencia-se assim que a validade do pensamento solitário é principalmente dependente da justificação de enunciados lingüísticos na comunidade efetiva da argumentação (APEL, 1994, p. 93).

Assim a crítica apeliana refuta o positivismo e o cientificismo, que ocultam esse reconhecimento recíproco das pessoas e postulam que a investigação dos fatos e o uso lógico do entendimento bastam para construir a ciência. A partir dessa análise é que se pode falar em perspectivismo moral.

\section{Perspectivismo moral: da polêmica à necessidade do consenso}

No item anterior pôde-se perceber que diferentes juízos científicos provêm de diferentes perspectivas morais. Mas o que é perspectivismo moral? Para compreendê-lo é necessário esclarecer o conceito de moral. A palavra moral vem do latim mores, que significa um conjunto de costumes e leis que são engendrados socialmente e que regem a vida das pessoas que pertencem à sociedade que os criou (VAZ, 1999, p. 419-422). Portanto ela é uma construção humana, inserida no tempo e permeada por diferentes culturas.

Pode-se afirmar, nessa perspectiva, que a moral não se fundamenta em uma Razão Universal ou transcendente, como afirmava Kant (1980, p. 161), mas sim no conjunto de condições históricas, sociais e culturais de um determinado grupo. Assim, não há uma moral que seja universal, ou seja, não há um conjunto de normas que seja vivido por todas as comunidades; cada cultura, cada tradição possui as suas, baseadas em valores próprios (ENGELHARDT, 1998, p. 25-27). Cabe ressaltar que não há uma moral que seja superior ou inferior. Cada qual foi estruturada segundo uma visão de mundo,

Rev. Pistis Prax., Teol. Pastor., Curitiba, v. 2, n. 1, p. 113-124, jan./jun. 2010 
uma cultura diferenciada (GEERTZ, 1989, p. 19), e, sendo assim, não é possível um julgamento. Tal atitude constituir-se-ia em etnocentrismo (LARAIA, 2000, p. 75), pois "reconhecer publicamente o valor das culturas é uma exigência ético-política de qualquer sociedade que afirme a dignidade da pessoa" (CORTINA, 2005, p. 154).

Aqui surge a polêmica: não há uma interpretação com maior autenticidade, com maior veracidade, o que existe são as interpretações. É necessário, enquanto sociedade, um consenso sobre essas interpretações. Mas como realizá-lo se todas as perspectivas possuem suas razões?

Um pensador, Jürgen Habermas, propõe uma teoria da comunicação como uma teoria crítica da sociedade, de modo que a ação comunicativa entre os interlocutores sociais é analisada segundo suas relações. Segundo o autor existem duas atividades que são características do homem: uma que se limita à manipulação dos objetos ou dos outros, que é denominada de atividade instrumental; e outra que busca a intercompreensão, o entendimento entre os parceiros, a qual é denominada atividade comunicativa. A segunda esboça uma possibilidade de consenso axiológico, pois se pressupõe não na força, na manipulação ou na coerção, mas sim na intercompreensão, pois o outro é uma pessoa, e mesmo que seja diferente, somente torna a comunidade rica em conteúdo para a argumentação.

A teoria crítica da sociedade funcionaria como uma teoria do comportamento, uma propedêutica, um conjunto de regras morais para a vida (HABERMAS, 1989, p. 39). No interior dessa teoria crítica, o conceito agir comunicativo corresponde às "ações orientadas para o entendimento mútuo", em que o ator social inicia o processo circular da comunicação e é produto dos processos de socialização que o formam, em vista da compreensão mútua e consensual. Nessa construção, a ideia de comunidade de comunicação - uma comunidade de direito ilimitado e idealmente isenta de violência - se apresenta como a referência obrigatória e última de toda prática humana dotada de sentido (TARNAS, 2000, p. 428).

A proposta de Habermas teoricamente auxiliaria na configuração de espaços de discussão e reflexão que possibilitariam um processo de consenso que atenuasse a questão da polêmica acerca do início da vida. Contudo, não se conseguiu configurar comunidades de argumentação que fossem isentas de coerção e pautadas em direitos ilimitados. A título de exemplo, cabe citar o exemplo da Organização das Nações Unidas (ONU), fundada em 1945 com o 
objetivo de manter a paz no mundo e proteger os Direitos Humanos, e que é utilizada diversas vezes por Estados como mecanismo para defesa de interesses que não correspondem ao benefício de todos. Assim, pode-se concluir que a possibilidade de uma universalidade valorativa ainda se constitui um desafio.

\section{REFERÊNCIAS}

APEL, K. O. Estudos de moral moderna. Tradução de Benno Dischinger. Petrópolis: Vozes, 1994.

BAECK, L. L'Essence du judaïsme. Paris: PUF, 1993.

BARCHIFONTAINE, C. P. Bioética e início da vida: alguns desafios. Aparecida: Idéias e Letras, 2004.

CORTINA, A. Cidadãos do mundo: para uma teoria da cidadania. Tradução de Silvana Cobucci Leite. São Paulo: Loyola, 2005.

ENGELHARDT Jr., H. T. Fundamentos da bioética. São Paulo: Loyola, 1998.

GEERTZ, C. Interpretação das culturas. Rio de Janeiro: Guanabara, 1989.

HABERMAS, J. Consciência moral e agir comunicativo. Tradução de Guido Almeida. Rio de Janeiro: Tempo Brasileiro, 1989.

KANT, I. Fundamentação da metafísica dos costumes. São Paulo: Abril Cultural, 1980.

LARAIA, R. B. Cultura: um conceito antropológico. 13. ed. Rio de Janeiro: Jorge Zahar, 2000.

REALE, G.; ANTISERI, D. História da filosofia. São Paulo: Paulinas, 1999.

RUSS, J. Pensamento ético contemporâneo. Tradução de Constança Marcondes. São Paulo: Paulus, 1999.

SANCHES, M. A. Bioética, ciência e transcendência: uma perspectiva teológica. São Paulo: Loyola, 2004.

SOUZA, O. de. Ele decifrou o código da vida. Revista Veja, n. 1865, p. 120-121, 2004. 
SOUZA, V. J. Projeto genoma humano: utopia do homem geneticamente perfeito. São Paulo: Loyola, 2004.

TARNAS, R. A epopéia do pensamento ocidental: para compreender as idéias que moldaram nossa visão de mundo. Tradução de Beatriz Sidou. 3. ed. Rio de Janeiro: Bertrand Brasil, 2000.

VAZ, H. L. Escritos de filosofia IV: instrodução à ética filosófica 1. São Paulo: Loyola, 1999.

WITTGENSTEIN, L. Investigações filosóficas. Tradução de José Carlos Bruni. São Paulo: Nova Cutural, 1991a.

Tractatus lógico-philosophicus. Tradução de José Carlos Bruni. São Paulo: Nova Cultural, 1991b.

Recebido: 12/09/2009

Received: 09/12/2009

Aprovado: 30/10/2009

Approved: 10/30/2009 